\title{
Conditioning Prices on Purchase History
}

\author{
Alessandro Acquisti \\ Hal R. Varian* \\ August 2001 \\ Revised: October 12, 2004 \\ Forthcoming, Marketing Science
}

\begin{abstract}
The rapid advance in information technology now makes it feasible for sellers to condition their price offers on consumers' prior purchase behavior. In this paper we examine when it is profitable to engage in this form of price discrimination when consumers can adopt strategies to protect their privacy.

Our baseline model involves rational consumers with constant valuations for the good being sold and a monopoly merchant who can commit to a pricing policy. Applying results from the prior literature, we show that although it is feasible to price so as to distinguish highvalue and low-value consumers, the merchant will never find it optimal to do so.

We then consider various generalizations of this model, such as allowing the seller to offer enhanced services to previous customers, making the merchant unable to commit to a pricing policy, and allowing competition in the marketplace. In these cases we show that sellers will, in general, find it profitable to condition prices on purchase history.
\end{abstract}

${ }^{*}$ H. John Heinz III School of Public Policy and Management, Carnegie Mellon University and School of Information Management and Systems, UC Berkeley. Research support from NSF grant 9979852 is gratefully acknowledged. We received helpful comments from Curtis Taylor, Ernesto Somma, and a number of seminar participants as well as from the anonymous referees. Email contact: acquisti@andrew.cmu.edu, hal@sims . berkeley. edu. 
Keywords: Internet Marketing, Personalized Marketing, Price Discrimination, Targeting, Privacy. 


\section{Introduction}

Many industries, including supermarkets, airlines, and credit cards, have compiled vast databases of individual consumer transactions and have used them to study purchase behavior and to make specific offers to individual consumers, via direct mail or other forms of targeted marketing. Many companies have become expert in using tracking tools to refine marketing strategies (see Bailey [1998], and Dayal et al. [2001]).

Since so many transactions are now computer mediated, and these computers can easily be networked to data centers, sellers now have the ability to access databases of past purchases in real time. This allows them to condition current offers to consumers on their previous purchase behavior. Sellers can offer each individual a different price, a particular prize or coupon, or personalized recommendations. With computer mediated transactions, price discrimination on an individual basis becomes quite feasible.

Collecting and analyzing such information is particularly easy in the online world. The HTTP protocol allows servers to set and read "cookies" that can store unique identifiers or information about a transaction. ${ }^{1}$ These cookies persist after the session has ended, so that the next time the user accesses the server (using the same account) the server can retrieve identification which can be matched with details of past interactions. Even without cookies, a variety of other mechanisms can be used to identify individual users, such as static IP addresses, credit card numbers, and direct user authentication.

There is evidence that Internet merchants have attempted to use "dynamic pricing" in order to price discriminate (see Taylor [2002] and Streifield [2001]). However, a long literature in economics, dating at least back to Stokey [1979], shows that, under certain conditions, a seller facing strategic customers cannot do better than committing to optimal single period pricing. Why, then, do both online and offline merchants invest so much on tracking technologies?

Our answer is based on considering the buyers' behavior. Although sellers can now easily use price conditioning strategies, consumers are far from defenseless. No one is forced to join a loyalty program. It is relatively easy to set one's browser to reject cookies or to erase them after a session is over. Consumers can use a variety of credit cards or more exotic anonymous pay-

\footnotetext{
${ }^{1}$ See Schartz [2001] for a history of Web cookies.
} 
ment technologies to make purchases anonymous or difficult to trace. In addition, consumers can voice their displeasure for pricing policies perceived as discriminatory or intrusive, as happened after the famous Amazon.com price experiment (Streifield [2001]).

Thus, even though sellers can post prices, observe choices, and condition subsequent price offers on observed behavior, buyers are also able to hide the fact that they bought previously. Hence, it is likely that sellers will have to offer buyers some benefits in order to induce them to reveal their identities.

In this paper we develop models of this strategic interaction between buyers and sellers in order to determine conditions under which sellers will find it profitable to condition prices on purchase history, and what measures, if any, buyers will adopt in defense.

Following earlier literature on intertemporal price discrimination, we find that in the simplest model, where consumers' valuations of the good being sold are constant, sellers do not want to condition current price offers on past behavior.

However, we also show that if the consumer's value for the good changes in certain ways as he or she makes more purchases, the seller will find it profitable to condition prices on past behavior. Although it has been known that changing values can make intertemporal price discrimination profitable, earlier literature focused on different discount rates and/or diminishing marginal utility of consumption.

By contrast, we focus on cases where the seller can induce the necessary change in consumer valuations by offering various forms of personalized enhanced services to prior purchasers, such as personalized discount coupons (common in supermarket loyalty clubs), lowered transactions costs (such as one-click shopping), or personalized services (such as personalized recommendations). We derive conditions describing when the use of such technologies is profitable to sellers and examine the impact of this sort of price discrimination on consumer welfare. Our analysis also allows us to define the conditions under which consumers will choose to reveal their personal information rather than hide behind anonymizing technologies.

This analysis takes place in the context of rational, fully informed consumers. We briefly examine the case where consumers are short-sighted and find that if enough customers are myopic, or the costs of using anonymizing technologies are too high, sellers will want to condition pricing on purchase history.

We then examine the large literature in which the seller cannot commit 
to prices; in this case, buyers will want to randomize their purchases in order to hide their type, leading to mixed strategy equilibria.

Finally, we examine the case of competition and find that if the availability of purchase history allows firms to offer higher value, customized offers to consumers, we will end up with various kinds of lock-in equilibria in which firms first invest in acquiring consumer information, and then exploit this information to provide personalized, albeit high priced, service to some consumers.

\section{Examples of price conditioning}

We use the term "personalized enhanced service" to describe a service that is valued by a consumer but can only be offered if there is prior interaction between the consumer and the merchant.

Typically such an enhanced service is based on information about the consumer's preferences. A consumer may frequent the same barber since that barber knows the consumer's preferences in haircuts. The barber, in turn, may charge a premium for his services since the consumer would have to incur costs in explaining to another barber exactly how his hair should be cut.

The same story applies to many other personalized services. People may stick with the same doctors, lawyers, accountants, dentists, butchers, and so on since these professionals know the consumer's tastes. Conversely, these professionals can provide different levels of service to loyal customers than to occasional customers.

As indicated in the introduction, it is now possible to automate such personalized enhanced services, since a seller can extract information about previous interactions with a buyer from a database in real time.

Expedited checkout. Amazon.com offers "one-click shopping" to previous customers, saving them the time and hassle of entering shipping and credit card information. Other merchants, such as Half.com and Buy.com have similar programs. At the same time, these merchants offer discounts to first-time buyers. For example, Half.com has offered "free shipping for new customers," "\$5 off purchases over $\$ 50$ for new customers," and so on. (To find other such examples, type "coupon"+ "new customers" into your favorite search engine. When we tried this 
recently on Google, we found about 15,000 hits.) The choice offered to the repeat customer is then: reveal your identity and save the cost of entering information, or hide your identity and get a lower price. Different customers may make different choices, allowing the seller to sort them appropriately.

Recommendation and reminder services. Amazon.com also makes personalized recommendations based on prior purchases. To the extent that this service is valuable, consumers may pay something of a premium to shop at Amazon. Similarly, many online merchants offer "reminder services," which remind the buyer about birthdays, anniversaries, and other repeated events.

Supermarket loyalty programs. Most supermarket chains now offer loyalty programs that reward frequent shoppers with low prices, coupons, and targeted offers. The targeted offers are made via direct mail or printed on the back of the receipt. These targeted offers are personalized, in that the nature of the offer depends on prior purchase behavior.

Consumer preferences. Hotels retain data on whether consumers prefer smoking or non-smoking rooms and may allow expedited checkin to repeat customers; airlines retain information on seating preferences and other similar data. Casinos retain data on gambling preferences and credit information, allowing them to better service repeat customers. This sort of information can only be available if there is a record of purchase history.

\subsection{Common features of the examples}

The examples above contain several common features:

- Repeated interactions between seller and customer, with the buyer being able to recognize the returning customer, and modify its offering accordingly.

- Personalized enhanced services such as expedited checkout, recommendations, personalized coupons, and so on, that may be valued differently by frequent and/or high-value purchasers. 
- These enhanced services typically have a low marginal cost to the seller, but high value to frequent purchasers.

- Often "list prices" are publicly quoted (online prices, supermarket prices) while the discounts are often personalized, sometimes via public offers (web coupons) sometimes via private offers (direct mail or coupons printed on the back of a receipt.)

In this paper we present a series of models that exhibit these features. We study sellers that can track consumers over repeated purchases, and consumers that may adopt defensive technologies to avoid being tracked. We investigate various properties of these models, such as when it is profitable to condition prices, when the conditioning involves "first high price, then low price" or the reverse, what is the impact on consumer welfare, and what happens if privacy-enhancing technologies such as anonymized purchases are feasible.

\section{Literature review}

Our research contributes to three interrelated areas of the economic and marketing literature: the literature on intertemporal price discrimination, the literature on consumer addressability, and the literature on economic aspects of personal privacy.

\subsection{Intertemporal price discrimination.}

The earliest contribution relevant to our research in the area of intertemporal price discrimination is Stokey [1979]. Stokey shows that intertemporal price discrimination is never optimal for a monopoly seller who can commit to future prices. Salant [1989] extends Stokey's result to the case of multiple types and shows that it follows from the linearity of the constraints in the problem. Riley and Zeckhauser [1983] find a "no haggling" result that is also related to the linearity issue examined in Salant [1989].

Several authors have examined intertemporal price discrimination in models in which the seller is unable to commit to future prices. This is not the focus of our paper, but it is certainly relevant to the practice. Obviously, it is most relevant when price offers can be made privately via direct mail, telephone solicitation, personalized coupons and the like. 
This literature uses the term "ratchet effect" to describe situations in which consumers who have signaled higher willingness to pay for a product tend to receive higher prices, even though the consumers attempt to avoid this outcome. See, for example, Freixas et al. [1985], Weitzman [1980], and (particularly relevant to our research) Hart and Tirole [1988], who study the strategies for sellers who are unable to commit to pricing policies in a repeated purchase game with incomplete information.

The above papers, with the commitment and non-commitment cases consider a monopoly seller. Other works - such as Fudenberg and Tirole [1998], Villas-Boas [1999, 2004], Fudenberg and Tirole [2000], and Chen and Zhang [2001] —investigate generalizations in both monopolistic and oligopolistic markets.

Fudenberg and Tirole [1998] ask what happens when the ability to identify particular consumers may vary across goods. In particular, they consider a model of goods upgrades and buy-backs where customers may be anonymous or "semi-anonymous." Fudenberg and Tirole [2000] analyze a duopoly in which some consumers remain loyal and others defect to the competitor, a phenomenon they refer to as "customer poaching." Villas-Boas [1999] finds that two firms in a duopoly can compete by lowering prices to attract the competitor's previous customers. Villas-Boas [2004] shows that targeted pricing by a monopolist who cannot commit to future prices may make it worse off. Finally, Chen and Zhang [2001] demonstrate a similar result in the case of a duopoly. To escape this impasse, Chen and Zhang [2001] propose a "price for information" strategy, with firms pricing less aggressively in order to learn more about their customers, a phenomenon related to the lock-in model we develop below.

In our paper, we allow the seller to identify individual buyers and condition pricing on purchase history of individual consumers. Furthermore, we analyze both the cases of a monopolistic seller with and without commitment, and focus on understanding the advantages and disadvantages that customers can gain from revealing personal information to sellers when they may also adopt a variety of defensive strategies (in particular, we consider scenarios when incremental purchases of a good can have higher utility than earlier purchases due to enhanced service based on the information previously provided by the customer). We also extend our model to the case of competitive sellers in which the purchase history of consumers provides a competitive advantage by allowing firms to tune offers to individual tastes, leading to "partial lock-in equilibria" where some consumers who value the 
enhanced services remain with a single seller, while others switch.

Our results also relate to the empirical literature on marketing and customer information, such as McCulloch et al. [1996] and Rossi and Allenby [1999], who have examined the value of customers' purchase histories and the advantages of targeted pricing schema, and Montgomery et al. [forthcoming], who have shown how clickstream data can be used to predict user online behavior for marketing purposes.

\subsection{Consumer addressability}

In the marketing literature, identification of specific customers is often called "customer addressability," and is viewed as a prominent feature of "interactive marketing." See Blattberg and Deighton [1991], McCulloch et al. [1996], Rossi and Allenby [1999], and Elsner et al. [2004] for an overview of various issues raised by these capabilities.

The term "customer addressability" is usually applied to situations where customers can be identified by a characteristic such as a zip code, which is a predictor of the valuation they might place on a good. Examples of this literature include Ulph and Vulkan [2000, 2001], Chen et al. [2001], and Chen and Iyer [2002].

Our focus on "conditioning prices on purchase history" is related to the marketing literature's discussion of "customer addressability." "Customer addressability" is essentially a form of first-degree price discrimination, using identity as a signal of willingness-to-pay. "Conditioning on purchase history" is essentially a form of second-degree price discrimination, with previous behavior as a signal of willingness-to-pay. As is typically the case, seconddegree price discrimination involves the strategic response of consumers to the pricing strategies set by the seller. Fudenberg and Tirole [2000] use the term "behaviorally based price discrimination" to describe what we call "conditioning prices on purchase history."

Perhaps the easiest way to clarify the difference between "addressability" and "behaviorally based" or "conditioning" effects would be to observe the following: few consumers would change their zip code to get a lower price on a book they purchase online, but many may well delete a cookie or delay purchase in order to get a better price. Hence in our paper we are able to answer the question of what happens when the consumer is not only rational but may have access to anonymizing technologies of different costs. 
Our work can also be compared to Kim et al. [2001], who study personalized reward programs in a repeat consumers/one-time consumers setting. While Kim et al. [2001] aim at understanding what type of reward program a seller should offer to its customers, we ask, more generally, under what conditions price discrimination based on purchase histories is optimal, in a model where the difference between repeat and one-time consumers is not exogenous but endogenously determined.

\subsection{Economic aspects of personal privacy}

Economic theorists have long been concerned with asymmetric information, though only recently have they begun to examine the economic implications of consumer privacy in formal models. Two papers in this area are related to our research: Calzolari and Pavan [2001] and Taylor [2002].

Calzolari and Pavan [2001] study contracting environments with two principals (e.g., two merchants) that interact sequentially with one common agent (the consumer). They assume that the consumer's tastes for the goods sold by the merchants are perfectly correlated and find that the transmission of information about the consumer between merchants may lead to increases in welfare and consumer surplus when the goods are complements. Calzolari and Pavan [2001]'s analysis however does not cover the case of merchants using customer data to offer personalized enhanced services, nor the case of users adopting defensive technologies.

Taylor [2002] also studies the market for customer information. Taylor finds that the welfare implications of the various technologies depend on the sophistication of the consumers. He finds that consumers fare poorly and firms fare well under an "open privacy" regime (where sale of customer information is permitted) when consumers are myopic. When customers are more sophisticated, firms benefit from keeping their customers' information private. His analysis, however, does not focus on the possibility that the 'anonymity' regime can be made endogenous through the consumer's decision process, who can opt for or against using privacy enhancing technologies.

In this paper we contribute to this literature by considering how the seller can use customer information not only for price discrimination but also to offer enhanced, personalized services, and by addressing a larger spectrum of responses by individual consumers, that include both delaying purchases and adopting anonymizing technologies. Thus we are also able to discuss certain welfare implications of interest in the current privacy debate, for the 
part which relates to the use of anonymizing shopping technologies and the consequences of regulating certain forms of price discrimination.

In summary, our contribution to the various strands of literature described above is as follows.

- We offer a simple algebraic and geometric treatment of the classic results that sellers will not want to engage in intertemporal price discrimination when consumers are sophisticated and valuations are constant.

- This classic result creates a paradox: why are sellers willing to invest so much in acquiring purchase history if they are unable to take advantage of it? We provide two answer:

- First, we briefly examine the relevant (but perhaps obvious) point that sellers will want to condition prices on past behavior if a large enough fraction of the consumer population is myopic or if anonymizing technologies are too costly or difficult to use.

- Second, we show that sellers condition prices if they can offer personalized enhanced services that high-value and low-value consumers value differently. Examples include: personalized coupons, expedited checkouts, recommendations, and other personalized services.

- The assumption of personalization plays a critical role in our model since it rules out merely offering enhanced services (i.e., a more valuable product) to all consumers. By its nature, a personalized service can only be offered once the seller has information about a consumer who has purchased before. The interaction between this sort of personalization and price discrimination has not, to our knowledge, been previously highlighted in the literature.

- We go on to compare consumer and producer welfare in conditioning and flat-price regimes, shedding some light on the privacy debate by analyzing the use of anonymizing technologies.

- We briefly compare our results to the literature where firms cannot commit to future prices, and examine the impact of consumers delaying purchases versus making anonymous purchases on equilibrium outcomes. 
- We develop a model of competitive sellers in which the purchase history of consumers provides a competitive advantage by allowing firms to tune offers to individual tastes. This imposes a switching costs on consumers, since they would lose their personalized services by switching to a competitor. This leads to a "partial lock-in equilibrium" where some consumers who value the enhanced services remain with a single seller, while others switch.

\section{The baseline model}

We begin with a simple model of a single profit-maximizing seller of a good that can be provided at zero marginal cost.

We assume that the seller has a mechanism for recording purchase histories of customers. This could be based on technologies such as loyalty program identifications, credit card numbers, static Internet addresses, and HTTP cookies, or other such devices, but we will refer to the mechanism simply as a "cookie."

We also assume that consumers may have mechanisms to avoid being tracked, such as deleting cookies from their browser, using different credit card numbers, or adopting other privacy enhancing technologies such as anonymous payments. We will refer to such mechanisms universally as an "anonymizing technology."

New customers come to the seller and are offered a price. Their decision about whether to purchase at this price is observed. The second time they come to the seller the price they are offered can be conditioned on their earlier behavior. The following list summarizes the possible actions the seller can take depending on whether or not a cookie is observed and what it indicates about prior behavior.

No cookie. The seller offers a price and records whether or not the customer purchases. It sets a cookie indicating whether or not purchase took place at the offered price.

Cookie shows customer bought before at price offered. The seller offers a price which may depend on the details of the previous purchase.

Cookie shows customer did not buy before at price offered. The seller offers a possibly different price. 
We approach the seller's problem from the perspective of mechanism design. For simplicity we restrict ourselves to two consumer types and two periods. Let $v_{H}$ be the high-value type's willingness to pay for one unit of consumption, and let $v_{L}$ be the low-value type's willingness to pay for one unit of consumption. Let $\pi$ indicate the fraction of the population that has the high value.

We will assume that if the consumer is indifferent, he will act in the manner preferred by the seller, since the seller could always cut a price by a penny if it were profitable to do so. For simplicity, we also assume a zero discount rate. As with any model of price discrimination, we also rule out resale.

Obviously, if the seller sets a flat price of $v_{H}$ each period, it will make a profit of $2 \pi v_{H}$ and if it sets a flat price of $v_{L}$ each period, it will make a profit of $2 v_{L}$. The maximum profit available from flat pricing is therefore $\max \left\{2 \pi v_{H}, 2 v_{L}\right\}$.

We are interested in whether the seller can do better by some form of individual conditioning that will allow price discrimination so that the highvalue person pays more than the low-value person.

\subsection{All consumers myopic}

Myopic consumers are those who base their purchase decision on the price that they see today, not recognizing that the price they face on the next purchase may depend on today's behavior. We present this case as a baseline for comparisons to more interesting scenarios below.

If consumers are myopic, the seller can offer a price of $v_{H}$ in the first meeting with the consumer. If the consumer does not purchase at this price, the seller can offer a price of $v_{L}$ the second time.

This strategy results in sales of 2 units to the high-value population and 1 unit to the low-value population, yielding revenues of

$$
2 \pi v_{H}+(1-\pi) v_{L} .
$$

How does price conditioning affect overall welfare? There are two cases.

Case 1. $\pi v_{H}>v_{L}$. If conditioning were not possible, the seller would sell only to the high-value consumers. Allowing conditioning doesn't change the price the high-value consumers face, but does allow the seller to identify the low-value consumers. This allows the merchant to sell to the low-value 
consumers at $v_{L}$, giving the them zero surplus from the purchase. Hence overall welfare (producer plus consumer surplus) rises, but this is entirely due to the increased profit received by the seller.

Case 2. $\pi v_{H}<v_{L}$. If conditioning were not possible, the seller would sell to everyone at price $v_{L}$. If conditioning is feasible, it will be profitable when

$$
\pi>\frac{v_{L}}{v_{H}}\left(\frac{1}{2-v_{L} / v_{H}}\right) .
$$

Thus, there will be a set of values of $\pi$ determined by

$$
\frac{v_{L}}{v_{H}}>\pi>\frac{v_{L}}{v_{H}}\left(\frac{1}{2-v_{L} / v_{H}}\right),
$$

for which the seller would sell to everyone if it did not have a way to condition, but chooses to restrict output when a conditioning technology is available.

It follows that the high-value consumers lose under conditioning and the low-value consumers are no worse off (though they consume in one period rather than two). The seller is better off due to selling at a higher price to the high-value consumers, but worse off from losing one period of revenue from the low-value consumers. If the seller voluntarily chooses to condition, it must be better off, but overall welfare is reduced due to price conditioning.

\subsection{All consumers sophisticated}

High-value consumers may eventually come to recognize that purchasing at a high price is not the best strategy, since it guarantees that they will face a high price in the future.

Let us suppose that consumers are sophisticated enough to adopt an anonymizing technology to avoid establishing a purchase history or to delay purchase.

Let $p_{H}$ be the present value (in this case, the sum) of the prices charged to the high-value person, and $p_{L}$ the present value of the prices charged to the low-value person. Let $x_{H}$ be the total amount consumed by the high-value type and $x_{L}$ the total amount consumed by the low-value type.

The optimization problem facing the seller is:

$$
\begin{aligned}
& \max _{x_{H}, x_{L}, p_{H}, p_{L}} \pi p_{H}+(1-\pi) p_{L} \\
& v_{H} x_{H}-p_{H} \geq v_{H} x_{L}-p_{L}
\end{aligned}
$$




$$
\begin{aligned}
v_{H} x_{H}-p_{H} & \geq 0 \\
v_{L} x_{L}-p_{L} & \geq v_{L} x_{H}-p_{H} \\
v_{L} x_{L}-p_{L} & \geq 0 .
\end{aligned}
$$

The first constraint represents the self-selection constraint that the highvalue type cannot gain by imitating the low-value type; the second constraint represents the participation constraint that the high-value type must receive non-negative surplus. The last two inequalities state the same constraints for the low-value type.

It is clear that due to the linearity of the problem $x_{L}$ and $x_{H}$ can only take on the values $\{0,1,2\}$. Working through these 8 cases, it can be shown that there are only 3 undominated outcomes pricing patterns: the two we have already described (sell at flat price only to high-value consumers, sell at flat price to both types) and a discriminatory pricing policy.

The discriminatory pricing policy takes the form $\left(x_{H}, x_{L}\right)=(2,1)$, where the pricing strategy is such to induce the high-value consumers to purchase twice, and the low-value consumer to purchase only once.

Plugging these values into the self-selection constraints, it is easily seen that the prices that support this policy are $p_{L}=v_{L}$ and $p_{H}=v_{H}+v_{L}$, which yield a profit of $\pi v_{H}+v_{L}$.

When does this exceed the profit from flat pricing? That is, when do we have

$$
\pi v_{H}+v_{L}>\max \left\{2 \pi v_{H}, 2 v_{L}\right\} ?
$$

The following result, which is basically the classic Stokey [1979] result, shows the answer is "never."

Fact 1 (Conditioning is not optimal.) If consumers are sophisticated, the seller does at least as well by setting a flat price as it does by conditioning prices on past behavior.

Proof. Writing out the necessary inequalities in 6 we have

$$
\begin{aligned}
& \pi v_{H}+v_{L}>2 \pi v_{H} \\
& \pi v_{H}+v_{L}>2 v_{L} .
\end{aligned}
$$

Adding these together gives a contradiction.

We can provide a simple and intuitive explanation of this result. Refer to Figure 1 where we have plotted the demand curve for total consumption for 


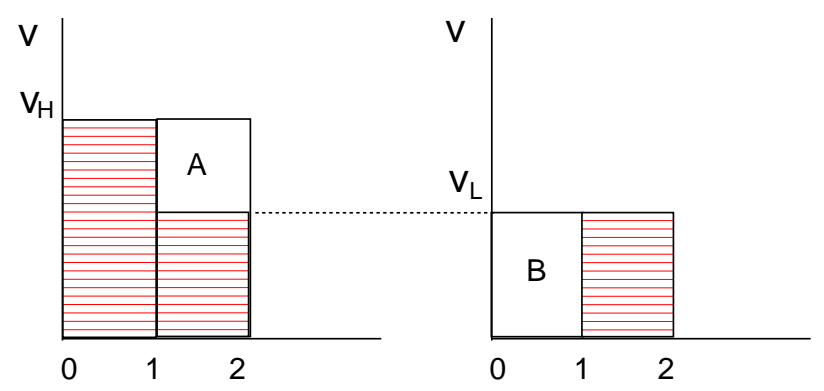

Figure 1: Demand curves, with shaded area indicating revenue.

two groups of consumers. The shaded part of the curve equals the revenue extracted by the seller under these prices. It is easy to see that if $A>B$, charging only $v_{H}$ yields more revenue, and if $B>A$ charging the $v_{L}$ yields more revenue. Hence one of these two flat pricing strategies must dominate differential pricing.

Intuitively, if selling to the high-value customers is more profitable than selling to both high- and low-value customers, then the seller wants to always sell to those customers. There is no advantage to cutting its price to sell to the low-value customers. Or, to put it another way: the seller cannot find it profitable to price discriminate since the high-value type can always choose the behave identically to the low-value type.

As we have indicated, the result that price discrimination is not profitable when the seller can commit to prices and consumers have stationary valuations has been derived by Stokey [1979], Salant [1989], and Riley and Zeckhauser [1983].

However, note that in our framework we allow the seller to condition pricing on purchase history of individual consumers, whereas most of the earlier literature only considered posted prices. Indeed, Stokey describes her model as one that applies to a "new product" such as a book or a movie that is offered in the first period at one price to all consumers and may subsequently be offered at a different price to all consumers in later periods.

Our model, by contrast, allows for personalized prices for existing products such as airline tickets or soap powder in which new and old, or frequent and infrequent consumers face different prices.

Nevertheless, we find that with sophisticated consumers our model has the same "reduced form" as the Stokey model. This is basically a consequence 
of the revelation principle: both the Stokey-Salant model and the model we examine are equivalent to the same mechanism design problem.

The result that sellers will not want to condition prices on purchase history is somewhat disconcerting since sellers invest many millions of dollars in computer systems to allow them to collect data to allow them to do exactly that. Though experimentation with such systems has only gone on for a few years in the online world, loyalty programs for airlines travelers and supermarket shoppers have been around for decades. Such programs commonly offer special prices to consumers with different purchase histories. But the results described above show that, at least in the simplest model, such behavior is not profitable. What is missing from this model?

\section{$5 \quad$ Profitable conditioning}

We consider two extensions of the model that allow for profitable conditioning.

- If a large enough fraction of consumers are myopic, or adopting anonymizing technologies is too costly, price conditioning may be profitable. This is obvious, but is quite empirically relevant, so we spell out the exact conditions for profitability in Section 5.1.

- If the value of the second unit of consumption is different from the value of the first unit of consumption, conditioning may be profitable.

In the standard analysis of quality or quantity discrimination, utility is assumed to be a concave function of quality/quantity. In that case diminishing marginal utility makes the second unit less valuable than the first. A more interesting assumption, in our context, is to examine the case where the second unit of consumption is more valuable than the first.

This could arise because the second purchase from the merchant is more efficient or pleasant than the first one, because the seller offered enhanced services of some form, enabled by the information the customer has revealed during the first purchase. Examples could be targeted recommendations, personalized service or content, one-click shopping, prizes, or a variety of other enhanced services. This "increasing marginal utility" case has not been examined in the previous literature, but is easy to handle in our framework in Section 5.2. 


\subsection{Some consumers are myopic}

Suppose that a fraction $m$ of each type is myopic, with a fraction $1-m$ being sophisticated. This case is undoubtedly realistic, but relatively straightforward in terms of analysis, so we will conduct only a cursory examination.

Assume that the seller conditions prices on purchase history by first charging a high price to everyone and then offering a low price to those who did not purchase.

The low-value consumers and the sophisticated high-value customers will wait for second period to buy at the low price. The myopic high-value consumers pay the high price each period. The revenue the seller receives is therefore

$$
2 m \pi v_{H}+(1-m \pi) v_{L} .
$$

This will exceed the revenue from flat pricing when

$$
m \pi>\max \left\{\frac{2 \pi v_{H}-v_{L}}{2 v_{H}-v_{L}}, \frac{v_{L}}{2 v_{H}-v_{L}}\right\} .
$$

Hence if the fraction of myopic consumers is large enough, the seller will want to condition prices on purchase history.

Note that, as usual, the presence of unsophisticated consumers can affect the welfare of the sophisticated consumers. Suppose that all consumers would pay a high price in the absence of myopic consumers. Then, if enough myopic consumers are present, the monopoly seller will want to condition prices and the sophisticated high-value consumers will be better off. On the other hand, if all consumers would pay a low price in the absence of myopic consumers, the presence of a sufficient number of myopic consumers would make the sophisticated consumers worse off.

What we have called "myopia" could also simply be a rational response to the inconvenience associated with defensive measures against price discrimination. If the material and immaterial costs of using anonymizing technologies are too high, even economically sophisticated consumers may find it not worth the bother, particularly if they are not technologically sophisticated or if their opportunity cost of time is particularly high (as it may be for the case of the high consumer type). These costs can also be endogenous to the model, in the sense that the seller may develop its selling platform with the goal of making the adoption of defensive technologies prohibitively costly for the consumer. The impact of various sorts of costs to anonymous purchases is formally examined by Acquisti [2003]. 


\subsection{Personalized enhanced services}

While Maskin and Riley [1984] consider second-degree price discrimination when marginal utility may be decreasing, it is interesting in our scenario to consider what happens when incremental purchases of the good have higher utility than earlier purchases due to enhanced service based on the information previously provided by the customer.

For simplicity, we will assume that the personalized enhanced service can be provided at zero marginal cost by the seller. The examination of the case of positive marginal costs is carried out in Acquisti [2003] and offers no substantial differences.

Let $v_{H 1}$ represents the value of the first unit of consumption for the highvalue consumer, and $v_{H 2}$ the value of the second unit of consumption. Define $v_{L 1}$ and $v_{L 2}$ similarly. Of course, we assume that

$$
v_{H 1}>v_{L 1}
$$

Utility for the high-value consumer can take on 3 values $\left(0, v_{H 1}, v_{H 1}+v_{H 2}\right)$, and likewise for the low-value consumer. Thus there are $2^{3}=8$ cases, as before.

The analysis mimics that in Section 4.2. The seller can again flat-price at the high or low prices, but the most interesting case is where the seller uses price-conditioning to have the high-value type consume twice and the lowvalue type consume once. The self-selection constraints for this conditioning solution in this case are

$$
\begin{aligned}
v_{H 1}+v_{H 2}-p_{H} & \geq v_{H 1}-p_{L} \\
v_{H 1}+v_{H 2}-p_{H} & \geq 0 \\
v_{L 1}-p_{L} & \geq v_{L 1}+v_{L 2}-p_{H} \\
v_{L 1}-p_{L} & \geq 0
\end{aligned}
$$

which can be transformed to

$$
\begin{aligned}
v_{H 2}+p_{L} & \geq p_{H} \\
v_{H 1}+v_{H 2} & \geq p_{H} \\
p_{H} & \geq v_{L 2}+p_{L} \\
v_{L 1} & \geq p_{L} .
\end{aligned}
$$

These inequalities are plotted in Figure 2. 


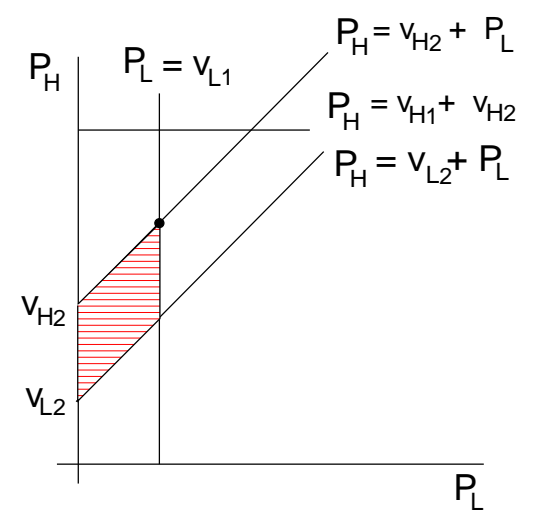

Figure 2: Self-selection constraints.

We are interested in the pricing plan $p_{H}=v_{H 2}+v_{L 1}$ and $p_{L}=v_{L 1}$ which induces the high-value consumers to purchase twice, and the low-value consumer to purchase only once.

For this to be feasible, we need to verify that the horizontal line determined by $p_{H}=v_{H 1}+v_{H 2}$ passes above this optimum. Algebraically, this requires:

$$
v_{H 1}+v_{H 2}>v_{H 2}+v_{L 1},
$$

Making the cancellation we see that this condition reduces to assumption (9).

The revenue from price conditioning exceeds the revenue from flat pricing when

$$
\begin{aligned}
& \pi v_{H 2}+v_{L 1}>\pi v_{H 1}+\pi v_{H 2} \\
& \pi v_{H 2}+v_{L 1}>v_{L 1}+v_{L 2} .
\end{aligned}
$$

Note that the right-hand side of these inequalities are the profits assuming that the enhanced service is offered to each type on the second purchase.

Making the obvious cancellations gives us the following result.

Fact 2 (When is conditioning profitable?) Conditioning prices will maximize profits if and only if

$$
\begin{aligned}
v_{L 1} & >\pi v_{H 1} \\
\pi v_{H 2} & >v_{L 2} .
\end{aligned}
$$

in which case $p_{H}=v_{H 2}+v_{L 1}$ and $p_{L}=v_{L 1}$. 
As a corollary, we have

Fact 3 (Relative valuations.) If conditioning is profit maximizing, then the high-value purchaser must value the enhanced services relatively more than the low-value user:

$$
\frac{v_{H 2}}{v_{H 1}}>\frac{v_{L 2}}{v_{L 1}} .
$$

Proof. Divide the second inequality by the first in the previous fact.

For example, one-click shopping may be more valuable to those who consume more frequently, or to those who have a higher value of time, which may easily be correlated with the valuation for the good in question. A similar observation follows for recommendation services or the other examples described in Section 2.

Note that it follows from this proposition that if both types have the same value for the enhanced service, the necessary inequalities cannot be satisfied and price conditioning cannot be profit maximizing.

It is also worth noting that if the second purchase has lower utility than the first, due to diminishing marginal utility of consumption, then price discrimination can easily be optimal, even without personalized services. This is the classic case examined in Salant [1989].

Note that the seller makes a profit of $\pi v_{H 2}+v_{L 1}$ in our model since it sells to both types at $v_{L 1}$ first period and only to the high-value type second period. If the "enhanced service" were not personalized, the seller could offer it to first-period consumers as well as second-period consumers. This would yield a profit of $\max \left\{2 \pi v_{H 2}, 2 v_{L 2}\right\}$ which is easily seen to be larger than the profit from price conditioning. As in Section 4, conditioning is not profitable for a quality enhancement that is not personalized. Price conditioning is profitable when the enhanced service can only be offered to second-time customers; i.e., the service depends on information revealed by the first purchase.

This particular pattern of behavior clearly rests heavily on the assumption of commitment on the part of the seller. We explore how the results change when this assumption is relaxed in Sections 6 and 7 .

\subsection{Value and cost of enhanced technology}

A referee raised the question of whether the cost of the enhanced service always had to be less than the value to the consumers in order for it to be 
adopted by the seller. The answer is that the high-value type has to place a value on the service that exceeds its cost, but this is not required for the low-value type.

To see this, let us suppose that there is a fixed cost $C$ and marginal cost of zero of implementing the enhanced service but that price conditioning is nevertheless more profitable than not conditioning. Algebraically, this means

$$
\begin{aligned}
& \pi v_{H 2}+v_{L 1}-C>2 \pi v_{H 1} \\
& \pi v_{H 2}+v_{L 1}-C>2 v_{L 1} .
\end{aligned}
$$

Adding these two inequalities together and simplifying, we have

$$
\pi\left(v_{H 2}-\pi v_{H 1}\right)>C,
$$

which says that the value of the enhanced service to the high-value consumers must exceed its cost. However, the impact of the enhanced technology on the low-valuation types can be anything consistent with the equilibrium inequalities in Fact 2.

Note that once the investment in information technology to track customer purchases and provided enhanced services is made, the marginal costs are so low that the service could be provided to everybody. However, the enhanced service is withheld from the low-value customer in order to squeeze more rent from the high-value consumer. This is the usual sort of inefficiency from second-degree price discrimination.

Acquisti [2003] has shown that the optimal conditioning result is robust to other cost specifications and variations in the model, such as: costs of adopting anonymizing technologies, costs of visiting a seller, costs of entering (and re-entering) information under different types of login/account technologies, and other variations.

\subsection{Welfare effect of conditioning}

How does price conditioning affect social welfare? The appropriate surplus calculations are shown in Table 1. Note that in terms of total welfare, conditioning fits between the two other cases. Conditioning dominates flat pricing when the alternative is selling only to the high-value type, but not when the alternative is selling to both types.

More specifically, if $v_{L 1}+v_{L 2}<\pi\left(v_{H 1}+v_{H 2}\right)$, and the inequalities in Fact 2 are satisfied, allowing firms to use cookies makes the society as a whole 


\begin{tabular}{rrrr} 
Case & Consumer & Producer & Total \\
& Surplus & Surplus & Surplus \\
\hline \hline Sell only to high-value & 0 & $\pi\left[v_{H 1}+v_{H 2}\right]$ & $\pi\left[v_{H 1}+v_{H 2}\right]$ \\
Condition prices & $\pi\left[v_{H 1}-v_{L 1}\right]$ & $\pi v_{H 2}+v_{L 1}$ & $\pi\left[v_{H 1}+v_{H 2}\right]+(1-\pi) v_{L 1}$ \\
Sell to both & $\pi\left[v_{H 1}+v_{H 2}-v_{L 1}-v_{L 2}\right]$ & $v_{L 2}+v_{L 1}$ & $\pi\left[v_{H 1}+v_{H 2}\right]+(1-\pi)\left[v_{L 1}+v_{L 2}\right]$
\end{tabular}

Table 1: Surplus calculations.

better off. The welfare ordering of the outcomes is the same as the ordering of total quantity sold, which is consistent with the welfare analysis in Varian [1985].

Consumers are generally opposed to price discrimination because they think that if discrimination were not allowed they would end up with lower prices. However, as economists are happy to tell them, when discrimination is not allowed all consumers may well end up facing higher prices.

Policies that make customer tracking infeasible, such as enforcing the use of technologies for anonymous shopping, may well have the perverse effect of damaging consumer welfare for exactly the same reason: the profitable non-discriminatory equilibrium ends up with monopoly pricing rather than competitive pricing.

\section{Timing}

We have seen that the seller will condition prices on purchase history when it is able to provide an enhanced service that is relatively more attractive to high-value consumers. In this case, the present value of the payments will be

$$
\begin{aligned}
p_{H} & =v_{H 2}+v_{L 1} \\
p_{L} & =v_{L 1} .
\end{aligned}
$$

Since we are assuming that the seller can commit to price plans, it appears that this present value can be divided between the two periods in arbitrary ways. However, whether or not that is the case depends on the tools that the high-value buyer has to defend himself against the price discrimination.

Consider an overlapping generations model where consumers visit an online store at most twice. If they have no cookie indicating a prior visit, they are charged $p_{0}$. If they have a cookie indicating that they bought on a prior visit, they are charged $p_{b}$. If they have a cookie indicating that they did not buy on their earlier visit, they are charged $p_{n}$. 
One way to implement the pricing system described in equations (21-22) is to charge

$$
\begin{aligned}
& p_{0}=v_{H 1} \\
& p_{b}=v_{L 1}+v_{H 2}-v_{H 1} \\
& p_{n}=v_{L 1} .
\end{aligned}
$$

In the second purchase the high type pays $v_{L 1}$ plus a premium equal to the incremental value of the enhanced service.

Why wouldn't the high-value types want to visit the store, reject the offered price, and then receive the more attractive price on the second visit? The answer: because if they don't buy on the first visit, they don't get the personalized enhanced service on the second visit. By construction, the highvalue buyers are indifferent between paying the higher price and getting the enhanced service to paying the low price without it. That is:

$$
v_{H 2}-p_{b}=v_{H 2}-\left[v_{L 1}+v_{H 2}-v_{H 1}\right]=v_{H 1}-v_{L 1} .
$$

In other words, consumers cannot "eat their cookie" (shop anonymously) and "have it too" (still receive the enhanced service.) ${ }^{2}$

In the real world, offers to "new customers only" can typically be utilized by "old customers" if they are willing to sacrifice other benefits that they get from being repeat customers. These benefits are exactly what drives our model: customers are not willing to sacrifice their personalized enhanced services in order to get a lower price. ${ }^{3}$

This pricing plan is only one way to implement the profit-maximizing solution. Another way to achieve the same present value is to charge

$$
\begin{aligned}
& p_{0}=v_{L 1} \\
& p_{b}=v_{H 2} \\
& p_{n}=v_{L 1} .
\end{aligned}
$$

Here everyone is charged a low price on first visit, and those who buy then are charged high price on the second visit, at which time only the highvalue types purchase. Essentially, the seller is collecting information on the

\footnotetext{
${ }^{2}$ Low-value shoppers may want to pursue such an "eat-the-bait and switch" strategy, as we describe below in Section 8. However, in that section the sellers are forced to accept this behavior through the forces of competition.

${ }^{3}$ In reality sellers use a variety of stratagems to make it difficult or costly for old customers to pretend to be new customers: see 5.1.
} 
first visit which is then used to provide the enhanced service that only the high-value people are willing to pay for on the second visit.

For example, an online merchant learns billing information and shipping address on the first visit. On the second visit, the merchant can offer, for example, "one-click shopping," a service that frequent purchasers, or those with high time value, might find particularly valuable. Such an offer induces the high-value type to stay rather than pretend to be low-value. ${ }^{4}$

Which of these two pricing patterns might we expect? As observed in Section 2, in supermarket loyalty programs the occasional, first-period purchasers pay a higher price than second-period, frequent purchasers; in the frequent flier case the opposite can happen. The answer depends on the nature of the technology at the buyer's disposal. If the only way that the high-value consumer can imitate the low-value consumer is to refuse to purchase when faced with a high-price during the first visit to a store, then these two price profiles are equivalent.

But if the high-value consumer can shop anonymously and return to the seller appearing to be a consumer who never bought before, the profile that involves charging $p_{0}=v_{L 1}$ cannot be an equilibrium. For if this profile were offered, the high-value consumer would buy on his first visit (taking the "low introductory offer for new consumers"), delete his cookie (for example), and then return to buy again at the same price. True, he would not get the enhanced service, but his payoff would be $2\left(v_{H 1}-v_{L 1}\right)$, which is larger than $v_{H 1}-v_{L 1}$, the payoff from pricing plan (21-22).

Hence the only equilibrium price plan when anonymous shopping is not overly expensive for the consumer is to charge the high price first.

\section{No commitment}

What happens when the seller cannot commit to its second period behavior?

Let us return to the baseline model described in Section 5.2. If the most profitable strategy is to sell at the low price, the inability to commit doesn't affect the outcome.

\footnotetext{
${ }^{4}$ Below we describe some empirical results from Goolsbee and Chevalier [2003] that show that Amazon customers are much less price sensitive that Barnes and Noble customers, possibly because of the enhanced services that Amazon offers. See also Economist [2001].
} 
However, when the most profitable strategy is to charge the high price to all, it can be shown that inability to commit induces the high-value consumer to pursue a mixed strategy. The formal argument is similar to the one in Fudenberg and Tirole [1991] (pp. 402-405), but the following intuitive discussion illustrates the basic phenomenon.

Suppose that the high-value type accepts a first-visit price offer with $v_{L}<p_{1}<v_{H}$ with probability 1 . Then if the seller observes a rejection, it must be facing a low value type with probability 1 . It follows that the seller should then offer a low price less than or equal to $v_{L}$ on the second visit of this person. But that means that high-value type would gain by rejecting the first-period offer.

On the other hand, suppose the high-value type rejects with probability 1 when the price satisfies $v_{L}<p_{1}<v_{H}$. Since the low type will also reject, the seller gets no information, and will set $p_{2}=v_{H}-e$ for some small $e$. But then the high-value type would want to accept with probability 1 and get positive surplus in each period.

It follows that the high-value type must pursue a mixed strategy. At least some fraction of the time the high-value consumer will emulate the behavior of the low-value type, hoping that the seller will then cut the price in the second period (see Taylor [2002] and Fudenberg and Tirole [1991], pp. 402-405 for examples).

In equilibrium, the seller will charge the same prices as in the case of full commitment, but will make less profit due to the randomized strategy of the high-value type. ${ }^{5}$

Turning now to the case of enhanced services, we ask: "Can price conditioning be an equilibrium when sellers cannot commit to future pricing?" The answer is "yes," but there is a subtlety. When commitment is not possible, we have to worry about the sequencing of price offers.

Any first period price in which the high-value and low-value types behave differently will allow the seller to enforce a separating equilibrium during the second period. Hence the equilibrium in which the seller conditions must be interpreted as one in which the seller offers to the same price to everyone first period, $v_{L 1}$, and offers a price of $v_{H 2}$ second period.

However, we saw in Section 6 that offering the low price in the first

\footnotetext{
${ }^{5}$ Because profit is reduced due to randomization, there may be conditioning solutions that yield more profit than the flat price outcome when the discount rate is greater than one. We thank Curtis Taylor for this observation and for his very helpful discussion of these issues.
} 
period is an equilibrium only when the high-value buyer cannot anonymize his shopping habits; that is, the only way the high-value consumer has to imitate the low-value consumer is to delay purchase.

In practice, this is a case in which a seller is able to offer a coupon to new users only, in the hope of converting them into second-period customers. Of course, if anyone can pretend to be a new customer, this strategy is not effective in enforcing price discrimination, and so cannot be an equilibrium for a monopoly seller. (We examine a competitive equilibrium of this sort in a later section.)

If the high-value consumer can "anonymize" rather than just "delay," being unable to commit imposes a cost on the seller, in that it will not be able to implement a price conditioning solution. For example, AOL offers special "new customer" accounts that can be opened only by revealing credit card numbers that have not been applied before to a similar offer.

In addition, if the value of the enhanced service is such that price discrimination is not optimal, and flat-pricing at the high price is better than flat pricing at the low price, the lack of a commitment device might force the seller to adopt a mixed strategy in the first period as described above.

Which is the more realistic model, commitment or no commitment? The answer will depend on the circumstances. One way for the seller to commit to flat pricing is to publicly post prices. This is common in both supermarkets and online shopping, where most price discounting takes place via coupons of one sort or another. Posted prices, with coupons, give the seller the best of both worlds, allowing it to "commit" to prices, yet still offer personalized discounts.

This analysis thus far depends the fact that the model terminates after two periods. It would be desirable to examine a no-commitment model with several periods, but such an extension brings up several additional issues outside the scope of this paper. ${ }^{6}$

\section{Competition and conditioning}

Up until now we have been considering a monopoly seller. In this section we examine what happens when a large number of identical sellers compete for

\footnotetext{
${ }^{6}$ See Fudenberg and Tirole [1998], Villas-Boas [1999], Fudenberg and Tirole [2000], and Villas-Boas [2004] for models of this type.
} 
customers. We assume that these sellers cannot commit to future prices, and cannot tell whether customers have bought before from other firms.

As before, we assume each seller sets prices of $p_{0}$ if the customer has no cookie, $p_{b}$ if a cookie shows that a customer bought at $p_{0}$, and $p_{n}$ if the cookie shows that the consumer did not buy at $p_{0}$.

We also assume that the good can be provided at a constant marginal cost of $c \geq 0$. To avoid trivial cases we also assume $v_{H 1}>c$. Since we normalize the population size to 1 , the cost of selling one unit to a fraction $\pi$ of the population is $\pi c$. We also assume that the enhanced service can be provided at zero marginal cost; this makes no difference as long as the consumers' valuations of the enhanced service exceed its marginal cost.

There are several conceivable equilibria. Consumers could make their first purchase from a firm and then stay with it in order to receive enhanced services on the next purchase. Some consumers could switch to a competitor or delete their cookies in order to receive the "introductory" price of $p_{0}$. Or, possibly, everyone could switch sellers every period.

It is useful to define the incremental value of the enhanced service to each type:

$$
\begin{aligned}
e_{H} & =v_{H 2}-v_{H 1} \\
e_{L} & =v_{L 2}-v_{L 1} .
\end{aligned}
$$

We will spell out the analysis for the case where the Spence-Mirrlees condition holds,

$$
e_{L}<e_{H},
$$

and simply state the results for the reverse inequality, since the analysis is completely parallel.

There are three equilibrium conditions that must be satisfied:

1. Consumers must make optimal choices, which will impose a set of inequalities.

2. Profits are driven to zero, which is an equality.

3. Firms are profit maximizing, which requires comparing their price choices to alternative choices they might make.

Case 1. We first show that it is not an equilibrium for all firms to charge a flat price $p$ at which all consumers purchase. The zero profit condition 
requires $p=c$. Consider a single firm that raises its price by any amount less than $\min \left\{e_{H}, e_{L}\right\}$ and provides the (free) enhanced service. This will be an attractive option for some or all consumers, thereby increasing profit, showing that charging flat prices is not an equilibrium.

Case 2. All customers shop at the same store twice rather than switch. Consumer optimization requires

$$
\begin{aligned}
& v_{H 2}-p_{b} \geq v_{H 1}-p_{0} \\
& v_{L 2}-p_{b} \geq v_{L 1}-p_{0},
\end{aligned}
$$

or

$$
\begin{aligned}
& p_{b} \leq p_{0}+e_{H} \\
& p_{b} \leq p_{0}+e_{L} .
\end{aligned}
$$

Profit maximization will drive $p_{b}$ to satisfy

$$
p_{b}=p_{0}+e_{L},
$$

and competition ensures profits are driven to zero, which means

$$
p_{0}+p_{b}=2 c .
$$

Solving these two equations in two unknowns we have

$$
\begin{aligned}
& p_{0}=c-\frac{e_{L}}{2} \\
& p_{b}=c+\frac{e_{L}}{2} .
\end{aligned}
$$

In order to show that this is an equilibrium, we need to show that no single firm can increase its profit by changing its behavior.

Clearly no firm will want to lower its price. Will a single firm want to raise its price? By raising $p_{b}$ to $p_{0}+e_{H}$ the deviating firm will induce its low-value customers to switch to the competition, or delete their cookies, in order to purchase at price $p_{0}$. On the other hand the high-value customers will choose to pay the higher price. The profit from this pricing deviation will be less than the profit from the presumed equilibrium when

$$
p_{0}+\pi\left(p_{0}+e_{H}\right)+(1-\pi) p_{0}<p_{0}+p_{b}=2 p_{0}+e_{L},
$$


which reduces to

$$
\pi e_{H}<e_{L} .
$$

Note that this is a "lock-in" equilibrium: consumers face a cost of switching in the second period, because they would lose the enhanced service. While in Villas-Boas [1999] firms in a duopoly lower prices to attract the competitor's previous customers, here firms in a perfectly competitive market respond by charging low prices in the first period, then high prices in the second period, as in typical lock-in equilibria behavior described in Klemperer [1989, 1995]. In our case, the switching costs the consumers face are due to the fact that their current seller provides them with personalized enhanced services and switching to a new seller would eliminate these services.

Case 3. The low-value type switches to another seller or deletes its cookie, the high-value type remains.

This requires

$$
\begin{aligned}
& p_{b} \leq p_{0}+e_{H} \\
& p_{b} \geq p_{0}+e_{L} .
\end{aligned}
$$

Profit maximization now implies $p_{b}=p_{0}+e_{H}$. Profits come from everyone buying at $p_{0}$ during the first visit, and high-value types buying at $p_{b}$ and low-value types buying at $p_{0}$ during their second visit. Competition ensures that profits are driven to zero, implying

$$
p_{0}+\pi\left(p_{0}+e_{H}\right)+(1-\pi) p_{0}=2 c,
$$

or

$$
2 p_{0}+\pi e_{H}=2 c .
$$

Solving for equilibrium we have

$$
\begin{aligned}
& p_{0}=c-\frac{\pi e_{H}}{2} \\
& p_{b}=c+\frac{(2-\pi) e_{H}}{2} .
\end{aligned}
$$

For this to be an equilibrium no single firm can deviate from these prices and make a profit. If a single firm lowers $p_{b}$ to $p_{0}+e_{L}$, it will keep its lowvalue customers but make less revenue on the high-value customers. This 
will not be profitable when

$$
p_{0}+p_{b}=p_{0}+\left(p_{0}+e_{L}\right)<p_{0}+\left(p_{0}+\pi e_{H}\right),
$$

which is to say when

$$
e_{L}<\pi e_{H}
$$

This is a "partial lock-in" equilibrium, as only the low-value types find it attractive to switch. The firms find it more profitable to let them go than to keep them, since keeping them would require cutting the price to the high-value types.

Case 4. The high-value type switches sellers, and the low-value type remains. This requires

$$
\begin{aligned}
& p_{b} \geq p_{0}+e_{H} \\
& p_{b} \leq p_{0}+e_{L},
\end{aligned}
$$

which implies

$$
p_{0}+e_{L} \geq p_{b} \geq p_{0}+e_{H} .
$$

Hence this case cannot occur when $e_{H}>e_{L}$.

Here is a summary of the results.

Fact 4 (Equilibria with competition.) With identical competing firms we have

- It is never an equilibrium for all firms to charge a flat price.

- If $e_{L}<e_{H}$, then in equilibrium

- No consumers will switch when $e_{L}>\pi e_{H}$.

- Low-value consumers will switch when $e_{L}<\pi e_{H}$.

- High-value consumers will never switch.

- If $e_{L}>e_{H}$, then in equilibrium

- No consumers will switch when $e_{H}>(1-\pi) e_{L}$.

- High-value consumers will switch when $e_{H}<(1-\pi) e_{L}$. 
- Low-value consumers will never switch.

This equilibrium exhibits a form of "customer poaching," a term introduced by Fudenberg and Tirole [2000]. They analyze a duopoly in which some consumers remain loyal and others defect to the competitor. In their model switching costs are zero, firms offer partial substitutes a la Hotelling, services are not personalized, and firms can tell which firms consumers bought from previously. Their baseline case is long distance telecommunications service, which is quite different from our situation, due to the undifferentiated nature of the good being sold.

In our situation, the seller is able to provide a personalized service that is valuable to at least some of the consumers. This creates switching costs for the consumers, since they would then have to rebuild the relationship with the seller.

In some cases these switching costs may be relatively small-e.g., entering credit card information - but even relatively small switching costs can matter. Goolsbee and Chevalier [2003] estimate demand elasticities facing Amazon and barnesandnoble.com. They find that the demand curve facing Amazon is much more inelastic than that facing barnesandnoble.com, an effect that may be due to the more personalized environment offered by Amazon. If this hypothesis is correct, it may be that Amazon's investment in "enhanced services" may be a significant contribution to its competitive advantage. Note that offering such services often requires large expenditures in fixed cost to implement the system, but very small marginal costs to service each customer, consistent with the zero marginal cost assumption in this paper.

Note that prices will obviously be lower in either form of the competitive equilibrium than in the monopoly equilibrium, and that the difference in prices with and without the enhanced service will be $e_{H}$ or $e_{L}$, which is also lower than in the monopoly case.

Finally, we note that even though we have stated this model in terms of a large number of sellers, very similar results would follow with small numbers of sellers as the basic structure is that of Bertrand competition. However, if there are few sellers, the low-value customers would eventually exhaust the gains from switching. This is presumably why CD clubs and book clubs tend to offer a relatively static collection of CDs to new users: if the set was continually updated, the switching problem would be more severe. 


\section{Implications and conclusions}

What light does this analysis shed on the question of whether or not it is profitable to implement price conditioning in practice?

First, if one thinks that a large enough fraction of the potential population is myopic and ignores the impact of their current behavior on future offerings, or anonymizing technologies are too costly for the consumer, then it may be attractive to use conditioning. In fact, under the conditions discussed above, the unavailability of anonymizing technologies may have positive effects on consumer welfare.

Second, even if a sizable fraction of the population is sophisticated, it may make sense to implement conditioning if high-value consumers can be offered a price-service package that they find more attractive than that offered to low-value consumers. This can be achieved by either offering an enhanced service to repeat users or inferior service to repeat users who are attempting to mimic new users.

We have provided examples in Section 2 illustrating the fundamental problem of price discrimination: how to induce the high-value type to pay the high price rather than mimic the behavior of the low-value type. In practice, a combination of enhanced services for "loyal" customers and "basic service" for those high-value users who pretend to be new customers may be used.

Adopting technology that allows for price conditioning will be particularly attractive in industries with the following characteristics:

- Industries where transactions are computer mediated, so that consumer purchase histories can be consulted at the time a price offer is made and personalized enhanced services can be provided.

- Industries where the marginal cost of providing enhanced services to some customers is low, but their personalization provides significant advantages for certain customer types.

- Industries with considerable variation in user valuation for enhanced services of various sorts.

- Industries with repeat and frequent purchases.

- Industries where anonymous purchase is difficult or costly (or can be made so by the seller). 
The examples we have used as illustrations - travel, online purchases, and supermarkets - all exhibit these characteristics and various forms of price conditioning have been used in such industries. In these industries, significant initial investments in IT can lead to competitive advantages through personalized enhanced services whose marginal costs are extremely low for sellers but that create switching costs for buyers, thus making price discrimination feasible. In these industries, frequent purchases, large search costs, heterogeneity in preferences, and low costs of personalizing services and addressing heterogeneous requests make price discrimination optimal. As more and more transactions become computer mediated, such practices will likely become more common, and rather than being perceived as privacy-intrusive, they may lead to increased customer loyalty and increased total welfare.

\section{References}

Alessandro Acquisti. Essays on Privacy, Anonymity, and Tracking in Computer-mediated Economic Transactions. PhD thesis, UC Berkeley, 2003.

Joseph P. Bailey. Internet price discrimination: Self-regulation, public policy, and global electronic commerce. Technical report, The Robert H. Smith School of Business, University of Maryland, 1998.

Robert C. Blattberg and John Deighton. Interactive marketing: Exploiting the age of addressability. Sloan Management Review, 33(1):5-14, 1991.

Giacomo Calzolari and Alessandro Pavan. Optimal design of privacy policies. Technical report, Gremaq, University of Toulouse, 2001.

Yuxin Chen and Ganesh Iyer. Consumer addressability and customized pricing. Marketing Science, 21(2):197-208, 2002.

Yuxin Chen, Chakravarthi Narasimhan, and Z. John Zhang. Individual marketing with imperfect targetability. Marketing Science, 20(1):23-41, 2001.

Yuxin Chen and Z. John Zhang. Competitive targeted pricing with strategic customers. Technical report, Leonard N. Stern School of Business, New York University, and Columbia Business School, 2001. 
Sandeep Dayal, Helene Landesberg, and Michael Zeisser. Building trust online. McKinsey Quarterly, 4, 2001.

Economist. Amazon, the software company. Economist, December 18th 2001.

Ralf Elsner, Arnd Huchzermeier, and Manfred Krafft. Optimizing Rhenania's direct marketing business through dynamic multilevel modeling (DMLM) in a multicatalog-brand environment. Marketing Science, 23(2):192-206, 2004.

Xavier Freixas, Roger Guesnerie, and Jean Tirole. Planning under incomplete information and the ratchet effect. Review of Economic Studies, 52(2):173191, 1985.

Drew Fudenberg and Jean Tirole. Game Theory. MIT Press, Cambridge, MA, 1991.

Drew Fudenberg and Jean Tirole. Upgrades, trade-ins, and buy-backs. Rand Journal of Economics, 29(2):238-258, 1998.

Drew Fudenberg and Jean Tirole. Customer poaching and brand switching. Rand Journal of Economics, 31(4):634-657, 2000.

Austan Goolsbee and Judith Chevalier. Price competition online: Amazon vs Barnes and Noble. Quantitative Marketing and Economics, 1(2):203-222, 2003.

Oliver D. Hart and Jean Tirole. Contract renegotiation and coasian dynamics. Review of Economic Studies, 55(4):509-540, 1988.

Byung-Do Kim, Mengze Shi, and Kannan Srinivasan. Reward programs and tacit collusion. Marketing Science, 20(2):99-120, 2001.

Paul Klemperer. Price wars caused by switching costs. Review of Economic Studies, 56(3):405-420, 1989.

Paul Klemperer. Competition when consumers have switching costs: An overview with applications to industrial organization, macroeconomics and international trade. Review of Economic Studies, 62(4):515-539, 1995.

Eric Maskin and John Riley. Monopoly with incomplete information. Rand Journal of Economics, 15(2):171-196, 1984. 
Robert E. McCulloch, Peter E. Rossi, and Greg M. Allenby. The value of purchase history data in target marketing. Marketing Science, 15(4):321340, 1996.

Alan L. Montgomery, Shibo Li, Kannan Srinivasan, and John C. Liechty. Modeling online browsing and path analysis using clickstream data. Marketing Science, forthcoming.

John Riley and Richard Zeckhauser. Optimal selling strategies: When to haggle, when to hold firm. Quarterly Journal of Economics, 98(2):267289, 1983.

Peter E. Rossi and G. M. Allenby. Marketing models of consumer heterogeneity. Journal of Econometrics, 89(1-2):57-78, 1999.

Stephen W. Salant. When is inducing self-selection suboptimal for a monopolist? Quarterly Journal of Economics, 104(2):391-397, 1989.

John Schartz. Giving the Web a memory cost its users privacy. New York Times, September 42001. http://www. nytimes. com/2001/09/04/technology/04C00K.html.

Nancy Stokey. Intertemporal price discrimination. Quarterly Journal of Economics, 93(3):355-371, 1979.

David Streifield. On the web price tags blur: What you pay could depend on who you are. The Washington Post, September 272001.

Curtis R. Taylor. Private demands and demands for privacy: Dynamic pricing and the market for customer information. Technical report, Department of Economics, Duke University, 2002.

David Ulph and Nir Vulkan. Electronic commerce and competitive firstdegree price discrimination. Technical report, University College, London, 2000 .

David Ulph and Nir Vulkan. E-commerce, mass customization and price discrimination. Technical report, University College, London, 2001.

Hal R. Varian. Price discrimination and social welfare. American Economic Review, 75(4):870-875, 1985. 
J. Miguel Villas-Boas. Dynamic competition with customer recognition. RAND Journal of Economics, 30(4):604-631, 1999.

J. Miguel Villas-Boas. Price cycles in markets with customer recognition. RAND Journal of Economics, 35(3):forthcoming, 2004.

Martin Weitzman. The 'Ratchet principle' and performance incentives. Bell Journal of Economics, 11(1):302-308, 1980. 